\title{
Applications of linear programming to optimize the cost-benefit criterion in production processes
}

\author{
Marek Krynke ${ }^{1, *}$, and Krzysztof Mielczarek ${ }^{1}$ \\ ${ }^{1}$ Czestochowa University of Technology, Department of Production Engineering and Safety, \\ ul. Armii Krajowej 19B, 42-200 Czestochowa, Poland
}

\begin{abstract}
In this paper linear programming was shortly characterized. The implementation of some basic functions for Octave have been presented. It is the GNU General Public License program for the optimization the cost-benefit criterion in production processes. A problem of dividing production tasks between workstations was presented in way that the cost of the realization was the smallest. The final score of the course was obtained the computational environment Octave using the GLPK (GNU Linear Programming Kit) function.
\end{abstract}

\section{Introduction}

Management is the administration of an organization, whether it is a business, a not-forprofit organization, or a government body. Management includes the activities of setting the strategy of an organization and coordinating the efforts of its employees to accomplish its objectives through the application of available resources, such as financial, natural, technological, and human resources. The necessity to cope with the problem of the economic practice, limitations, the risk and the uncertainty are connected with it [1].

In production companies the process of directing refers not only to the attitude to an employee, but also to the attitude to sources [2]. It leads to the fact that correct application to the production system demands the professionalism and practical abilities of the interdisciplinary attempt at analysis of the manufacturing process. Decision-making is an integral part of modern management. Decisions are made to sustain the activities of all business activities and organizational functioning with the help of owned sources [3].

Taking important decisions many times causes a lot of problems. Decision making process can be regarded as a check-and-balance system. When one problem is solved another arises and so on, so decision making process is continuous and dynamic [4]. In making beneficial choices, mathematical modeling can be helpful. To present many of them it is possible to use the mathematical description called the task of linear programming [5]. Linear programming is a mathematical technique used in a variety of practical fields to maximize the useful output of a process for a given input. In general form the extreme of the function (the function of the objective) has to be found. Linear programming is

\footnotetext{
* Corresponding author: marek.krynke@wz.pcz.pl
} 
a method to achieve the best outcome in a mathematical model whose requirements are represented by linear relationships. Linear programming is a special case of mathematical programming (mathematical optimization) [6, 11-13].

\section{Problem of the linear programming. Computational environment Octave}

The linear programming is the most often applied model of the optimization on account of the existence of finding efficient algorithms of optimal solution. The intuitiveness of linear relations appearing in the mathematical model [7].

A few methods of solving tasks of the linear programming exist. A graphic method is simplest, however, its practical application is limited to tasks with two decision-making variables. Mathematically it is possible to prove, that searching the task of the linear programming by extremes of function (if it exists) will be acting in one of the tops of the figure, defined through imposed limitations (called the polyhedron of solutions). Rarely is the problem so simple, and, while increasing the number of searched parameters a number of dimensions of the answers, polyhedron is increasing. Now, there are very effective algorithms of the solution to this problems. A popular algorithm for linear programming is the simplex method. George Dantzig, while describing the „Origins of the Simplex Method, „noted that it was the availability of early digital computers that supported and invited the development of LP models to solve real-world problems. When Dantzig introduced his method in 1947, it was somewhat easier to sort out the details of the simplex method than to deal with the "where are we in the domain space" questions that are the core of interiorpoint approaches. The solution of a linear program is accomplished in two steps. In the first step, known as Phase I, a starting extreme point is found. Depending on the nature of the program, this may be trivial, but, in general, it can be solved by applying the simplex algorithm to a modified version of the original program. The possible results of Phase I are either that a basic feasible solution is found or that the feasible region is empty. The method allows to find solutions in short time and is applied in many popular solver [5, 8].

It is possible to solve problems where there is a large number of variables with the help of programs for numerical calculations e.g. MATLAB or Octave [9]. Octave is a free programme for numerical calculations (mathematical and engineering calculations). This language is intuitive and friendly (for a mathematician). With basic functionality in Octave there are operations on matrices and number of numerical methods solving linear and nonlinear problems. Octave is software featuring a high-level programming language, primarily intended for numerical computations. Octave helps in solving linear and nonlinear problems numerically, and it is used for performing other numerical experiments with the use of a language that is mostly compatible with MATLAB. In addition to being used on desktops for personal scientific computing, Octave is used in academia and industry. Octave has been built with MATLAB compatibility in mind, and shares many features with MATLAB. [10]. For many applications, where speed or generating 3D animation is not essential, Octave is more appropriate. Both programs are compatible with Linux, Windows, MAC OS and Android system.

\section{Analysis of the production tasks segmentation}

Production tasks segmentation is an important part of a production process. It is connected with the size of the profit and costs. Production tasks should be allocated in order for the profit made by the production system to be maximized while, at the same time, the costs are minimized. 
In this article a problem of dividing 5 production tasks between 4 workstations was presented in such a way that the cost of the realization was smallest. The following research problem was considered.

There are 4 machines whose available standard hours of work were given in Table 1 . With the help of these machines the production program of five products should be realized. Manufacturing cost (1 hour) of the machine $j$ for the one product $i$ are shown in Table 2. The production of every product can be divided in randomly between the machines. The hourly productivity of machines depends on which product is produced on a given machine. Individual value was given in Table 1. The production tasks should be allocated to machines in such a way so that the total cost of the realization of the production program is minimal.

Table 1. Productivity of individual machines depending on products [piece/hour].

\begin{tabular}{cccccc}
\hline \multirow{2}{*}{ Products } & M1 & M2 & M3 & M4 & $\begin{array}{c}\text { Planning for } \\
\text { production } \\
\text { [piece/month] }\end{array}$ \\
\cline { 2 - 5 } & 200 & 200 & 500 & 300 & 20000 \\
P1 & 700 & 250 & 300 & 200 & 25000 \\
P2 & 450 & 300 & 400 & 400 & 18000 \\
P4 & 400 & 300 & 200 & 300 & 15000 \\
P5 & 100 & 400 & 600 & 200 & 20000 \\
\hline $\begin{array}{c}\text { Available standard } \\
\text { hours of work } \\
\text { [hour/month] }\end{array}$ & 30 & 90 & 60 & 90 & \\
\hline
\end{tabular}

Table 2. Cost per piece of the machine $j$ for the product $i$ [PLN/hour].

\begin{tabular}{ccccc}
\hline \multirow{2}{*}{ Products } & \multicolumn{4}{c}{ Machines } \\
\cline { 2 - 5 } & M1 & M2 & M3 & M4 \\
\hline P1 & 10 & 25 & 10 & 40 \\
P2 & 10 & 30 & 35 & 25 \\
P3 & 10 & 30 & 10 & 10 \\
P4 & 30 & 15 & 15 & 25 \\
P5 & 25 & 30 & 50 & 10 \\
\hline
\end{tabular}

In order to describe this situation with mathematical model a way to characterise the allotted tasks with the help of numbers should be found. The first parameter is cost connected with the realization of individual products, and the second parameter is available standard hours of work. It is possible to describe cost per piece of the machine $j$ and the working time. An assessment of the effectiveness of work is a more difficult problem. In this example, the effectiveness of work is expressed through the productivity of individual machines. In the case of products which were already made on a given machine, determining their productivity is straight and quite accurate. However, in the case of a new product their preliminary estimation, and later correction will be necessary.

Designation:

$k_{j i}-$ cost for one working hours of the machine $i$ for product $j$,

$p_{i}$ - number of work units required at planning for production,

$h_{i}$ - available standard hours,

$w_{j i}$ - productivity of machines - number of work units ( 1 hour) for machine $i$ and product $j$, The monthly total cost of the realization of the production program are described as:

$$
\begin{aligned}
\cos t & =h_{11} \cdot k_{11}+h_{12} \cdot k_{13}+h_{13} \cdot k_{13}+h_{14} \cdot k_{14} \\
& +h_{21} \cdot k_{21}+h_{22} \cdot k_{22}+h_{23} \cdot k_{23}+h_{24} \cdot k_{24}
\end{aligned}
$$




$$
\begin{aligned}
& +h_{31} \cdot k_{31}+h_{32} k_{32}+h_{33} \cdot k_{33}+h_{34} \cdot k_{34} \\
& +h_{41} \cdot k_{41}+h_{42} \cdot k_{42}+h_{43} \cdot k_{43}+h_{44} \cdot k_{44} \\
& +h_{51} \cdot k_{51}+h_{52} \cdot k_{52}+h_{53} \cdot k_{53}+h_{54} \cdot k_{54}
\end{aligned}
$$

It is a function that should be minimized. At the same time, the available standard hours of work:

$$
\begin{aligned}
& h_{11}+h_{21}+h_{31}+h_{41}+h_{51} \leq 30 \\
& h_{12}+h_{22}+h_{32}+h_{42}+h_{52} \leq 90 \\
& h_{13}+h_{23}+h_{33}+h_{43}+h_{53} \leq 60 \\
& h_{14}+h_{24}+h_{34}+h_{44}+h_{54} \leq 90
\end{aligned}
$$

and requirement concerning production order - limitations of work units (size of the batch):

$$
\begin{aligned}
& h_{11} \cdot w_{11}+h_{12} \cdot w_{13}+h_{13} \cdot w_{13}+h_{14} \cdot w_{14}=20000 \\
& h_{21} \cdot w_{21}+h_{22} \cdot w_{22}+h_{23} \cdot w_{23}+h_{24} \cdot w_{24}=25000 \\
& h_{31} \cdot w_{31}+h_{32} w_{32}+h_{33} \cdot w_{33}+h_{34} \cdot w_{34}=18000 \\
& h_{41} \cdot w_{41}+h_{42} \cdot w_{42}+h_{43} \cdot w_{43}+h_{44} \cdot w_{44}=15000 \\
& h_{51} \cdot w_{51}+h_{52} \cdot w_{52}+h_{53} \cdot w_{53}+h_{54} \cdot w_{54}=20000
\end{aligned}
$$

Defined task is possible to be solved in the environment Octave. Fig. 1 shows a numeric code of the task to the solution into the console of Octave program. A structure of the code and individual elements was explained.

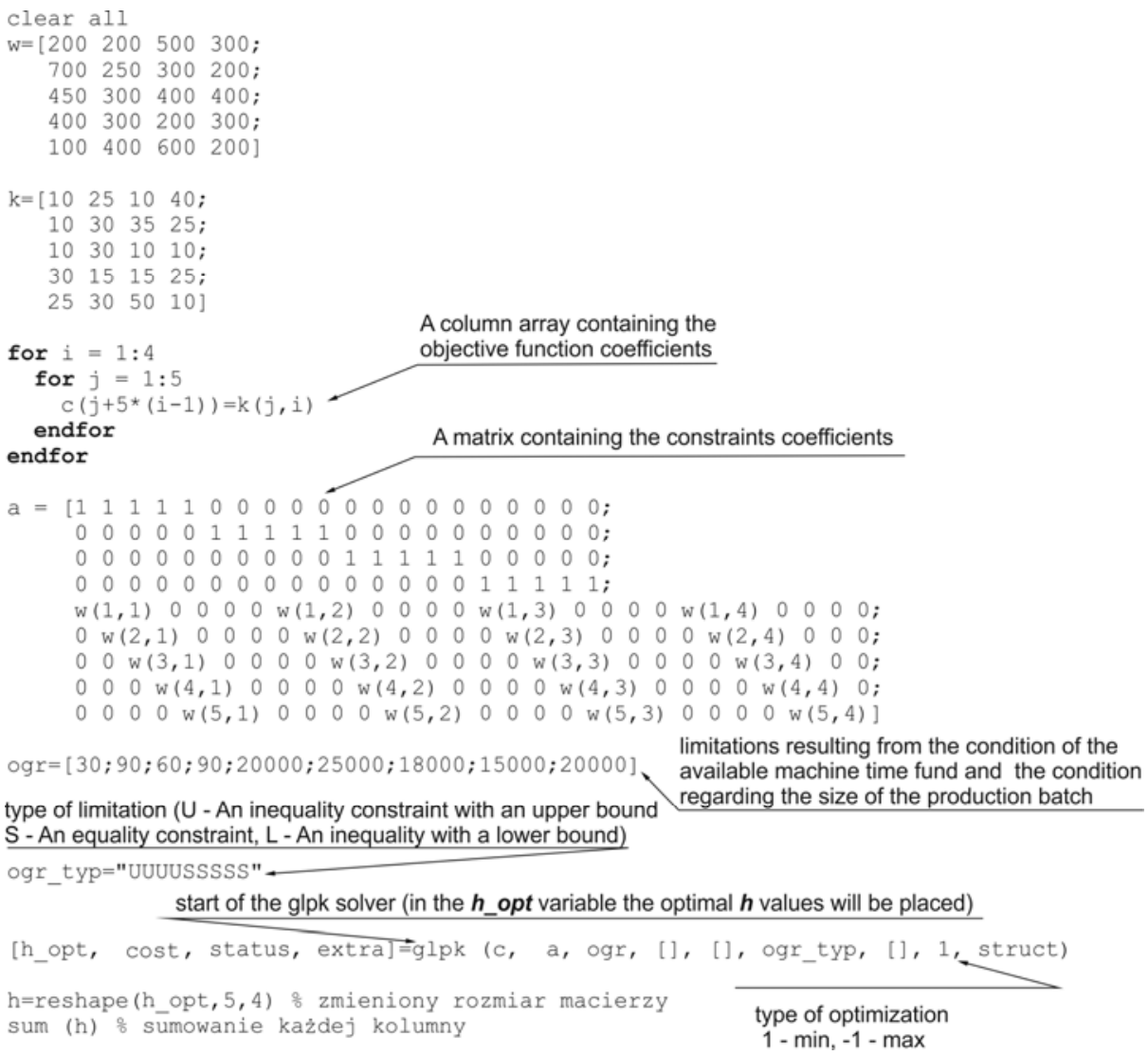

Fig. 1. Source code of the analysed problem prepared for solving in the environment Octave. 
After doing calculations in vector $h \_o p t$ optimal value of working hours for individual operation was written. A cost that was minimized is determined in the variable cost. More information about parameters can be obtained when help glpk is inscribed into the Octave console.

In Fig. 2 optimal assigning production tasks to machines was described. For a planned production process, the production of the product $\mathrm{P} 1$ will be the most effective only on the machine M3, the production of the product $\mathrm{P} 2$ on the machine M1 and M2, the production of the product $\mathrm{P} 3$ on the machine M3 and M4, the production of the product $\mathrm{P} 4$ on the machine M2 and the production of product P5 on the machine M2 and M4.

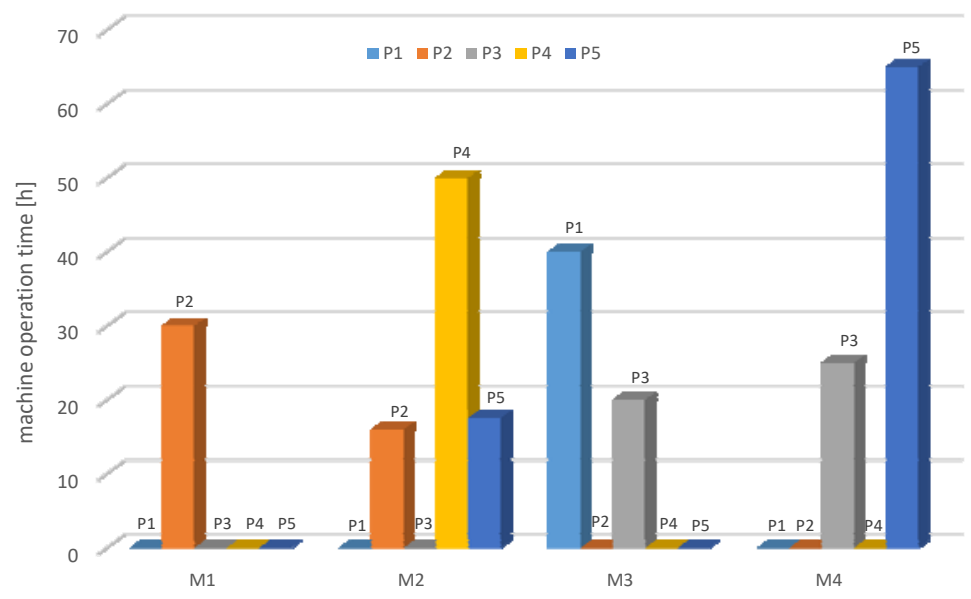

Fig. 2. Optimal assigning tasks to individual machines.

In Fig. 3a machine time fund against the background of available standard hours of work was presented. The most diversified production is on the machine M2. On this machine available standard hours of work were not fully exploited. It is beneficial because on this machine a large number of rearming can appear.

In Fig. $3 \mathrm{bO}$ a graph that compares the total cost of the realization of the production program for two extreme cases was presented. The first situation concerns the optimal solution; when costs are subjected to the minimization. For comparison, the second one shows a situation when costs were maximized.

a)

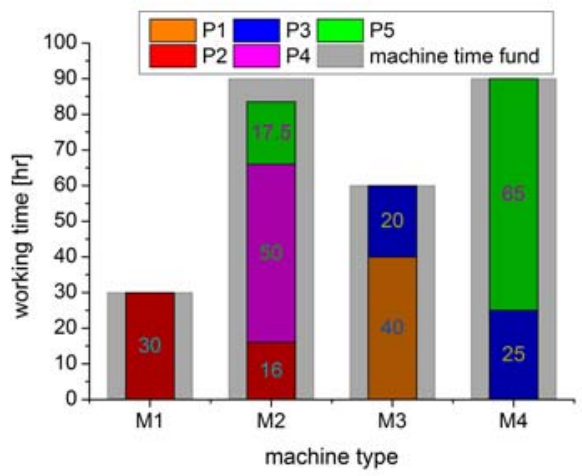

b)

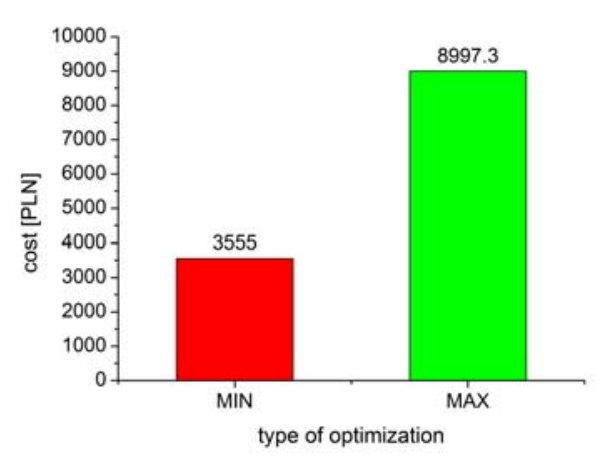

Fig. 3. Available standard hours of work (a), total cost of the realization of the production program in the case of the criterion the minimization and the maximization (b). 


\section{Summary}

At present, the approach towards matters of production process improvement must answer to contemporary developmental tendencies in a scope of company management in conditions of the market economy. Linear programming is one of the simplest ways to perform optimization. It helps solve some very complex optimization problems by making a few simplifying assumptions. It is possible to use the linear programming for the minimization of production costs as well as for the maximization of profits.

The presented example can, by analogy, be widened to a large number of machines and tasks as well as months. This mathematical model find application in many engineering problems e.g. the problem of optimal using stores, realization the cheapest order, etc.

\section{References}

1. R. Ulewicz, M. Nowicka-Skowron, 26th International Conference on Metallurgy and Materials, Total Quality Management in practice of polish metallurgical companies (Tanger Ltd., Ostrava, 2017)

2. D. Klimecka-Tatar, Production Engeenering Archives, 17 (2017)

3. K. Knop, J. Rosak-Szyrocka, 25th Anniversary International Conference on Metallurgy and Materials, Evaluating and improving the effectiveness of the rolling mill in the production of medium steel sections in the selected company from the metallurgical industry (Tanger Ltd., Ostrava, 2016)

4. M. Zasadzień, Production Engeenering Archives, 11 (2016)

5. M. Afsharian, V.V. Podinovski, EJOR, 268 (2018)

6. P. Saengudomlert, Optimization for communications and networks (Boca Raton, CRC Press, 2012)

7. A. Piechna, PiKI, 55 (2012)

8. S. Kreter, A. Schutt, P.J. Stuckey, EJOR, 266 (2018)

9. I. Azzini, R. Muresano, M. Ratto, CLS\&S, 52 (2018)

10. S. Nagar, Introduction to Octave: For Engineers and Scientists (Apress, NewYork, 2018)

11. N. Radek, J. Pietraszek, B. Antoszewski, Adv. Mat. Res.-Switz. 874, 29 (2014)

12. P. Szataniak, F. Novy, R. Ulewicz, $23^{\text {rd }}$ International Conference on Metallurgy And Materials, 778-783 (2014)

13. T. Lipinski, A. Wach, $23^{\text {rd }}$ International Conference on Metallurgy And Materials, $23^{\text {rd }}$ International Conference on Metallurgy And Materials, 778-783 (2014) 